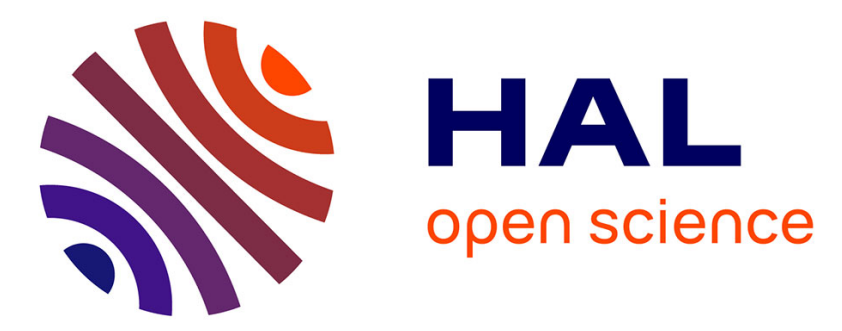

\title{
Radiopaque poly(e-caprolactone) as additive for X-ray imaging of temporary implantable medical devices
}

Rémi Samuel, Edouard Girard, Grégory Chagnon, Stéphane Dejean, Denis

Favier, Jean Coudane, Benjamin Nottelet

\section{- To cite this version:}

Rémi Samuel, Edouard Girard, Grégory Chagnon, Stéphane Dejean, Denis Favier, et al.. Radiopaque poly(e-caprolactone) as additive for X-ray imaging of temporary implantable medical devices. RSC Advances, 2015, 5, pp.84125-84133. 10.1039/c5ra19488a . hal-01369275

\section{HAL Id: hal-01369275 \\ https://hal.science/hal-01369275}

Submitted on 9 Nov 2018

HAL is a multi-disciplinary open access archive for the deposit and dissemination of scientific research documents, whether they are published or not. The documents may come from teaching and research institutions in France or abroad, or from public or private research centers.
L'archive ouverte pluridisciplinaire HAL, est destinée au dépôt et à la diffusion de documents scientifiques de niveau recherche, publiés ou non, émanant des établissements d'enseignement et de recherche français ou étrangers, des laboratoires publics ou privés. 


\title{
Radiopaque poly(3-caprolactone) as additive for X-ray imaging of temporary implantable medical devices
}

\author{
Rémi Samuel, ${ }^{\text {a }}$ Edouard Girard, ${ }^{\text {bcd }}$ Grégory Chagnon, ${ }^{\text {cd }}$ Stéphane Dejean, ${ }^{\mathrm{a}}$ Denis Favier, ${ }^{\mathrm{cd}}$ \\ Jean Coudane ${ }^{\mathrm{a}}$ and Benjamin Nottelet ${ }^{\star a}$
}

Implantable polymeric medical devices suffer from a lack of visibility under current clinical imaging techniques. To circumvent this problem, poly $(\varepsilon$-caprolactone-co- $\alpha$-triiodobenzoate- $\varepsilon$-caprolactone)s (PCL-TIB) containing from $3.5 \%$ to $24 \%$ of triiodobenzoate- $\varepsilon$-caprolactone units were synthesized as new $\mathrm{X}$-ray macromolecular contrast agents. Physico-chemical and thermal properties of PCL-TIBs were evaluated by ${ }^{1} \mathrm{H}$ NMR, SEC, DSC and TGA. Their potential as radio-opacifying additive for medical devices was evaluated by preparing polymeric blends of PCLTIB with various (co)polyesters. At first, in vitro X-ray visibility of PCL/PCL-TIB blends was evaluated. A more in depth characterization was then carried out based on PCL/PLA $50-P E G-P L A_{50}$ blends. The impact of PCL-TIB content on the mechanical properties of blends was evaluated by tensile tests. Stability of X-ray visibility was evaluated by ex vivo implantation of non-degraded blends and of blends degraded for 6 weeks in vitro. Finally, cytocompatibility was assessed by evaluating the proliferation of L929 fibroblasts on the blends.

\section{Introduction}

Medical imaging has a strong impact on modern medicine practice and participates to the raise of advanced applications including in vivo cell marking, early diagnosis of diseases, image-guided therapy or post-surgical medical devices followup. ${ }^{\mathbf{1 , 2}}$ This is in particular the case of X-ray imaging, a low cost imaging technique that has been used for over a century and provides good spatial resolution with no limit on tissue penetration depth. In the early 70's, X-ray computed tomography (CT) was developed to produce cross-sectional images of the body. The mechanism of CT imaging is based on the absorption of X-rays as they pass through tissues with distinct degrees of attenuation that depend on the atomic number and electron density of the tissues. ${ }^{3}$ The differences in absorption between bone, fat, water, and air yield high contrast images of anatomical structures. To achieve a signal that is sufficient for clinical purposes, contrast agents (CAs) are however generally required. The principle of CAs is to increase the signal to noise ratio (SNR) relative to surrounding tissues to provide clear discrimination

\footnotetext{
anstitute of Biomolecules Max Mousseron (IBMM) UMR 5247, Department of Artificia Biopolymers, CNRS, University of Montpellier, ENSCM, Faculté de Pharmacie, 15 avenue Charles Flahault BP14491, 34093 Montpellier Cedex 5, France.

${ }^{\mathrm{b}} \mathrm{CHU}$ de Grenoble, TIMC-IMAG, F-38000 Grenoble, France

'Université Grenoble Alpes, TIMC-IMAG, F-38000 Grenoble, France

${ }^{\mathrm{d}} \mathrm{CNRS}$, TIMC-IMAG, F-38000 Grenoble, France
}

between normal and pathological regions in areas of interest. ${ }^{1}$ CAs are therefore found in all molecular imaging modalities currently in use, including X-ray radiography/computed tomography (CT). Classical low molecular weight CT CAs or radio-opacifying agents include gold nanoparticles, heavy metal powders (tantalum), inorganic salts of heavy elements (barium sulfate, bismuth sulfide), or organic compounds containing a heavy atom (iodine).$^{4-6}$ Small-molecular mass CAs are however characterized by rapid extravasation and clearance. They are also known to induce recurrent problems like acute renal toxicity or adverse allergic and pseudo-allergic reactions. ${ }^{4,7}$ These factors, in addition to the ionizing character of X-ray, explain that X-ray imaging still represents today only $c a$. $7 \%$ of the medical images.

A renewed and strong interest is however currently witnessed based on two approaches. The first one is the development of micro-computed tomography $(\mu \mathrm{CT})$ application to soft tissues, where specific X-ray CAs with a selective biodistribution have been designed. ${ }^{\mathbf{8} 9}$ The second one is the development of macromolecular CAs. ${ }^{10,11}$ Indeed, polymeric biomaterials featuring radio-opacity attract considerable scientific attention since it is highly desirable to visualize medical devices such as cardiovascular implants, prostheses, orthopedic implants via routine X-rays computed tomography. In that frame, aliphatic polyesters are among the most common degradable polymers used in medical applications. Aliphatic polyesters include the 
well-known poly(lactide) (PLA), poly(glycolide) (PGA), poly( $\varepsilon$-caprolactone) (PCL) and their copolymers, like poly(lactic-coglycolic acid) (PLGA). This family of polymers has been a first choice for a variety of biomedical applications, ranging from surgical suture to implants or drug nanocarriers. ${ }^{12,13}$ This success story originated during the resorbable-polymer-boom of the 1970s and 1980s and is mostly due to their demonstrated biocompatibility and biodegradability that led to their validation by the regulatory agencies worldwide. Aliphatic polyesters and their copolymers are thermoplastics that present numerous advantages like tailorable degradation kinetics and mechanical properties, ease of shaping and manufacture. Their broad spectrum of properties can easily be tuned by the use for instance of lactic acid-based stereocopolymers, or copolymerization with the biocompatible hydrophilic poly(ethylene glycol) (PEG). ${ }^{14,15}$ This is therefore not surprising to find them as core materials in the innovation pipeline of medical imaging strategies.

However aliphatic polyesters, as most polymeric biomaterials, are transparent to X-rays. They are generally made radiopaque by addition of an X-ray absorbing additive such as metal powders, metal salt based on tantalum, barium, bismuth, gold etc. ${ }^{16-19}$ For example Lamsa et al. reported on a radiopaque stent composed of PLA96 with $25 \mathrm{wt} \%$ of $\mathrm{BaSO}_{4}$ that was used as radiopaque bioabsorbable biliary stents. ${ }^{20,21}$ To avoid leaching of potentially metallic compounds, organic-inorganic hybrids were also prepared via the sol-gel process starting from a dihydroxy-terminated polyester poly(1,4-butyleneglutarate) (PBG), PLA or PCL and a titanium alkoxide (TIPT) as titanium precursors. ${ }^{22}$ It was demonstrated that a transesterification reaction of the polymer chain occurring in situ led to organotitanium esters connecting organic and inorganic domains that demonstrated radio-opacity. ${ }^{23}$

To circumvent the problem of potential toxicity encountered with metallic additives ${ }^{24}$ organic radio-opacifiers containing heavy atoms such as bromine or iodine were also proposed. However, the resulting polyester/radio-opacifier blends also suffer from leaching problems that result in the loss of imaging capabilities and potential toxicities. To avoid leaching, Koole et al. reported recently on biocompatible and PLA-miscible iodinated contrast agent, namely (S)-2-hydroxy-3-(4iodobenzyloxy) propanoic acid that has a plasticizing effect due to structural compatibility with PLA. ${ }^{25}$ The blend obtained with $10 \mathrm{wt} \%$ contrast agent yielded about $25 \%$ attenuation compared to aluminum. However, although blend compatibility was improved, no covalent bond was still found between the PLA backbone and the organic opacifier.

To achieve this goal, two strategies are described. The first one relies on covalent grafting of radio-opacifiers to polymer backbone in a post-polymerization modification strategy. In a second approach, iodinated monomers are copolymerized to yield radiopaque copolymers. These methodologies have been applied to various polymeric materials including cellulose ${ }^{26,27}$ poly(meth) acrylates, ${ }^{3,28-35}$ polyurethanes, ${ }^{6,36,37}$ polyphosphazenes ${ }^{38}$ or polycarbonates. ${ }^{39}$ However, only few studies report on aliphatic polyesters conjugates for X-ray modalities. To the best of our knowledge, the first radiopaque polyester bearing iodine was described by our group. ${ }^{40}$ Poly( $\varepsilon$-caprolactone-co- $\alpha$-iodo- $\varepsilon$-caprolactone) (PCL-I) was synthesized by introducing iodine in the $\alpha$ position of the carbonyl group of PCL thanks to an anionic activation of PCL followed by substitution with iodine. Copolyesters containing from $10 \%$ to $25 \%$ of iodized-units were thus obtained. In another strategy iodinated PCLs were prepared by copolymerization of $\alpha$-iodo-e-caprolactone with $\varepsilon$-caprolactone. ${ }^{41,42}$ The X-rays opacity was assessed, and appeared high enough to be of interest for biomedical applications although stability of aliphatic carbone-iodine bond could be improved. More recently, Olsen et al. reported on the copolymerization of $\varepsilon$-caprolactone and 1,4,8-trioxaspiro-[4,6]-9-undecanone to yield after oxime ligation a copolyester containing $13 \%$ of iodizedunits. ${ }^{43}$ However, limited thermal stability of oxime grafts was reported. Other radiopaque biodegradable polyesters have been prepared by ring-opening polymerization of lactide and $\varepsilon$-caprolactone using an iodinated initiator, namely 2,2bis(hydroxymethyl)propane-1,3-diyl bis(2,3,5-triiodobenzoate). ${ }^{44}$ The resulting polyesters exhibited a radio-opacity of $60-124 \%$ relative to an aluminum sample of the same thickness and could be electrospun into nanofibers. Similarly, biodegradable radiopaque iodinated poly(ester-urethane) based on PCL oligomers and iodinated bisphenol containing up to $30 \mathrm{wt} \%$ iodine, ${ }^{45}$ or salicylate-based poly(anhydride-ester), ${ }^{46}$ have been reported. It should be noted that, whereas attenuation similar or even higher than aluminum and good cytocompatibility were shown with the poly(ester-urethane)s, cytotoxicity was observed towards L929 mouse fibroblasts with the iodinated salicylate-based poly(anhydride-ester)s.

Considering this limited number of radiopaque copolyesters available, and keeping in mind temporary implantable medical device as a final application, we aim in this work at providing a new radiopaque PCL for X-ray imaging with improved stability with respect to poly( $\varepsilon$-caprolactone- $c o-\alpha$-iodo- $\varepsilon$-caprolactone) (PCL-I). The synthesis of poly( $\varepsilon$-caprolactone-co- $\alpha$-triiodobenzoate- $\varepsilon$-caprolactone) (PCL-TIB) based on anionic activation and post-polymerization modification of PCL is first described. Thermal properties and stability compared to PCL-I are then discussed before evaluation of PCL-TIB cytocompatibility towards L929 fibroblasts. Finally, the potential of PCL-TIB as macromolecular radio-opacifier is assessed through the preparation of blends of PCL-TIB and PLA-PEG copolymers. Blends have been characterized in terms of mechanical and imaging properties with in particular evaluation of the X-ray visibility $e x$ vivo over a 6 weeks degradation period.

\section{Experimental part}

\section{Materials}

PCL $\left(\overline{M_{\mathrm{n}}} \approx 32000 \mathrm{~g} \mathrm{~mol}^{-1}\right), 2,3,5$-triiodobenzoic acid (TIBA, 98\%), thionyl chloride (97\%), lithium diisopropylamide (LDA, 2 $\mathrm{M}$ in THF/heptane/ethylbenzene), were purchased from SigmaAldrich (St-Quentin Fallavier, France). $\mathrm{NH}_{4} \mathrm{Cl}$ (>99\%) was obtained from Acros Organics (Noisy-le-Grand, France), technical grade $\mathrm{MgSO}_{4}$ from Carlo Erba (Val de Reuil, France), methanol ( $\mathrm{MeOH}, \geq 99.8 \%$ ), dichloromethane (DCM, $\geq 99.9 \%$ ) and anhydrous tetrahydrofuran (THF, $\geq 99.9 \%$ ) from Sigma- 
Aldrich (St-Quentin Fallavier, France). THF was distilled on benzophenone/sodium until a deep blue color was obtained. PrestoBlue ${ }^{\mathrm{TM}}$, Dulbecco's Modified Eagle Medium (DMEM/ F-12), Phosphate Buffered Saline (PBS), sterile Dulbecco's Phosphate Buffered Saline (DBPS), Fetal Bovine Serum (FBS), penicillin, streptomycin, and glutamine were purchased from Invitrogen (Cergy Pontoise, France). BD Falcon ${ }^{\mathrm{TM}}$ Tissue Culture Polystyrene (TCPS) 24-well plates were purchased from Becton Dickinson (Le Pont de Claix, France) and Viton ${ }^{\circledR}$ O-rings from Radiospares (Beauvais, France).

\section{Characterizations}

The number average molecular weight $\left(\overline{M_{\mathrm{n}}}\right)$ and dispersity $(\nexists)$ of the polymers were determined by size exclusion chromatography (SEC) using a Waters 515 HPCL pump fitted with a PLGel $5 \mu \mathrm{m}$ mixed C pre-column $(50 \times 7.5 \mathrm{~mm})$ a PLGel $5 \mu \mathrm{m}$ mixed $\mathrm{C}$ column $(600 \times 7.5 \mathrm{~mm})$ and a Waters 410 refractive index detector. The mobile phase was $\mathrm{CHCl}_{3}$ at $1 \mathrm{~mL} \mathrm{~min}{ }^{-1}$ flow and $25{ }^{\circ} \mathrm{C}$. Typically, the polymer $(5 \mathrm{mg})$ was dissolved in $\mathrm{CHCl}_{3}$ (1 $\mathrm{mL})$, and the resulting solution was filtered through a $0.45 \mu \mathrm{m}$ Millipore filter before injection of $20 \mu \mathrm{L}$ of filtered solution. $M_{\mathrm{n}}$ was expressed according to calibration using polystyrene standards.

For stability studies, polymers were analyzed by SEC using a Waters 515 HPCL pump fitted with a PLgel $5 \mu \mathrm{m}$ Guard column $(50 \times 7.5 \mathrm{~mm})$, a PLGel $10 \mu \mathrm{m} 500 \AA$ columns $(600 \times 7.5 \mathrm{~mm})$, a PLGel $10 \mu \mathrm{m} 50 \AA$ columns $(300 \times 7.5 \mathrm{~mm})$, Waters 2410 refractive index detector and Waters 2996 photodiode array detector. The mobile phase was THF at $1 \mathrm{~mL} \min ^{-1}$ flow and $25^{\circ} \mathrm{C}$. Typically, the polymer $(5 \mathrm{mg})$ was dissolved in THF $(1 \mathrm{~mL})$, and the resulting solution was filtered through a $0.45 \mu \mathrm{m}$ Millipore filter before injection of $20 \mu \mathrm{L}$ of filtered solution.

${ }^{1} \mathrm{H}$ NMR spectra were recorded at room temperature using an AMX300 Bruker spectrometer operating at $300 \mathrm{MHz}$. Deuterated chloroform was used as solvent, chemical shifts were expressed in ppm with respect to tetramethylsilane (TMS).

The thermal properties of the polymers were characterized by differential scanning calorimetry (DSC) and thermogravimetric analysis (TGA). DSC measurements were carried out under nitrogen on a Perkin-Elmer Instrument DSC 6000 Thermal Analyzer. Samples were submitted to a first heating scan from $20{ }^{\circ} \mathrm{C}$ to $110{ }^{\circ} \mathrm{C}\left(10^{\circ} \mathrm{C} \mathrm{min}{ }^{-1}\right)$ followed by a cooling ramp to $-65{ }^{\circ} \mathrm{C}\left(5{ }^{\circ} \mathrm{C} \mathrm{min}^{-1}\right)$ followed by an isotherm at $-65^{\circ} \mathrm{C}$ $(10 \mathrm{~min})$ and a second heating ramp to $180{ }^{\circ} \mathrm{C}\left(5^{\circ} \mathrm{C} \mathrm{min}^{-1}\right)$. Melting temperature $\left(T_{\mathrm{m}_{1}}\right)$ and melting enthalpy $\left(\Delta H_{\mathrm{m}_{1}}\right)$ were measured on the first heating ramp. Crystallization temperature $\left(T_{\mathrm{c}}\right)$ was measured on the cooling ramp. Melting temperature $\left(T_{\mathrm{m}_{2}}\right)$, melting enthalpy $\left(\Delta H_{\mathrm{m}_{2}}\right)$ and glass transition temperature $\left(T_{\mathrm{g}}\right)$ were measured on the second heating ramp. TGA thermograms were obtained under normal atmosphere on a PerkinElmer Instrument TGA 6 at a scanning rate of $10{ }^{\circ} \mathrm{C} \mathrm{min}{ }^{-1}$ from 30 to $400{ }^{\circ} \mathrm{C}$.

\section{Synthesis of triiodobenzoyl chloride (TIBC)}

2,3,5-Triiodobenzoyl chloride (TIBC) was obtained by reaction of 2,3,5-triiodobenzoic acid (TIBA) with thionyl chloride. In a typical experiment, TIBA (5 g, $10 \mathrm{mmol}$ ) was dissolved in thionyl chloride $(50 \mathrm{~mL})$ and the solution was heated to reflux under stirring for 16 hours. Excess thionyl chloride was distilled off under reduced pressure. Brown solid was obtained and purified by crystallization from hot tetrachloromethane. The resulting white solid needles were filtered and dried under vacuum. TIBC ( $60 \%$ yield) was characterized by NMR and FT-IR analyses (ESI Fig. S1 and S2 $\dagger$ ). FT-IR: acyl chloride band at 1759 $\mathrm{cm}^{-1} \cdot{ }^{1} \mathrm{H}$ NMR $\left(300 \mathrm{MHz} ; \mathrm{CDCl}_{3}\right): \delta(\mathrm{ppm})=7.9$ and $8.3(\mathrm{~s}, 2 \mathrm{H})$.

\section{Synthesis of poly( $\varepsilon$-caprolactone-co- $\alpha$-triiodobenzoate- $\varepsilon$ - caprolactone) (PCL-TIB)}

In a typical experiment (Table 1, sample PCL-TIB 8 ), PCL (17.5 mmol of CL unit, $2 \mathrm{~g}$ ) was dissolved in anhydrous THF $(300 \mathrm{~mL})$ in a four-necked reactor equipped with a mechanical stirrer and kept at $-40{ }^{\circ} \mathrm{C}$ under argon atmosphere. A solution of LDA (0.25 eq./CL unit, $2.2 \mathrm{~mL}$ ) was injected with a syringe through a septum and the mixture was kept at $-50{ }^{\circ} \mathrm{C}$ under stirring for $30 \mathrm{~min}$. After this activation step, TIBC (0.25 eq./CL unit, $2.3 \mathrm{~g}$ ) was added, the mixture was kept under stirring and maintained at $-40{ }^{\circ} \mathrm{C}$. After $30 \mathrm{~min}$, the reaction was stopped by addition of a saturated solution of $\mathrm{NH}_{4} \mathrm{Cl}(100 \mathrm{~mL})$ and $\mathrm{pH}$ was adjusted to 7 with $1 \mathrm{M} \mathrm{HCl}$. The polymer was extracted with dichloromethane $(3 \times 150 \mathrm{~mL})$. The combined organic phases were washed three times with distilled water $(3 \times 150 \mathrm{~mL})$, dried on anhydrous $\mathrm{MgSO}_{4}$ and filtered. After partial solvent evaporation under reduced pressure, the polymer was recovered by precipitation in cold methanol and dried overnight under vacuum. The polymer was obtained with an average yield of $85 \%$ and $8 \%$ substitution with respect to CL units (ESI Fig. S3 $\dagger$ ).

${ }^{1} \mathrm{H}$ NMR: $\left(300 \mathrm{MHz} ; \mathrm{CDCl}_{3}\right): \delta(\mathrm{ppm})=8.3$ and $7.6(2 \mathrm{H}, \mathrm{CH})$, $4.0\left(2 \mathrm{H}, \mathrm{CH}_{2}-\mathrm{O}\right), 2.3\left(2 \mathrm{H}, \mathrm{C}(\mathrm{O}) \mathrm{CH}_{2}\right), 1.6\left(4 \mathrm{H}, \mathrm{C}(\mathrm{O}) \mathrm{CH}_{2}-\mathrm{CH}_{2}-\right.$ $\left.\mathrm{CH}_{2}-\mathrm{CH}_{2}-\mathrm{CH}_{2}-\mathrm{O}\right), 1.4\left(2 \mathrm{H}, \mathrm{C}(\mathrm{O}) \mathrm{CH}_{2}-\mathrm{CH}_{2}-\mathrm{CH}_{2}-\mathrm{CH}_{2}-\mathrm{CH}_{2}-\mathrm{O}\right)$.

\section{Tensile tests}

Sample plates were prepared by dissolution of the polymer blends in dichloromethane followed by solvent evaporation under atmospheric pressure and in dark. Mechanical properties of the polymers were determined by performing tensile mechanical tests on dogbone-style tensile specimens $(\approx 15 \times 2$ $\times 0.5 \mathrm{~mm}^{3}$, section $=1 \times 10^{-6} \mathrm{~m}^{2}$, ESI Fig. S6 $\left.\dagger\right)$ at $37{ }^{\circ} \mathrm{C}$ with GABO Eplexor® $1500 \mathrm{~N}$ testing machine equipped with a $25 \mathrm{~N}$ cell force at a crosshead speed rate of $5 \mathrm{~mm} \mathrm{~min}^{-1}$. Each sample was analyzed in triplicate and Young's modulus ( $E, \mathrm{MPa})$, and yield strain $(Y, \%)$ were expressed as the mean value of the three measurements. $E$ was calculated using the initial linear portion of the stress/strain curves.

\section{Polymer blends preparation}

Two types of polymer blends were prepared and used to yield sample films with $0.5 \mathrm{~mm}$ thickness. Films were prepared by solvent evaporation method in acetone and used for X-ray imaging tests. First series of blends consisted of PCL-TIB and pristine PCL and were prepared for in vitro evaluation of PCL-TIB/PCL blends radio-opacity with respect to aluminum wedge reference. Weight ratios of PCL-TIB and PCL were 
Table 1 Conditions for the synthesis of poly( $\varepsilon$-caprolactone-co- $\alpha$-triiodobenzoate- $\varepsilon$-caprolactone) $(P C L-T I B)$ from commercial PCL $\left(M_{n}=\right.$ $\left.32000 \mathrm{~g} \mathrm{~mol}^{-1} ; \ominus=1.8\right)$

\begin{tabular}{llllllll}
\hline Sample & Temperature $\left({ }^{\circ} \mathrm{C}\right)$ & LDA eq. & CTIB eq. & SD (\%) & $M_{\mathrm{n}}\left(\mathrm{g}\right.$ mol $\left.{ }^{-1}\right)$ & $D$ & Distribution \\
\hline PCL-TIB $_{3.5}$ & -50 & 0.5 & 0.25 & 3.5 & 24000 & 1.7 \\
PCL-TIB $_{8}$ & -40 & 0.25 & 0.25 & 8 & 19000 & Monomodal \\
PCL-TIB $_{12}$ & -30 & 0.25 & 0.25 & 12 & 17000 & 3.6 & Monomodal \\
PCL-TIB $_{24}$ & -30 & 0.5 & 0.5 & 24 & 9500 & Weak shoulder
\end{tabular}

adjusted to yield polymer blends containing $0,5,10,15$, and $25 \mathrm{wt} \%$ of iodine, which corresponds to PCL-TIB weight ratios in blends of $0 \mathrm{wt} \%, 25 \mathrm{wt} \% \mathrm{PCL}^{-\mathrm{TIB}_{8}}, 50 \mathrm{wt} \% \mathrm{PCL}^{-\mathrm{TIB}_{8}}, 55 \mathrm{wt} \%$ PCL-TIB $_{12}$ and $95 \mathrm{wt} \%$ PCL-TIB 12 , respectively.

Second series of blends was prepared from PCL-TIB and $\mathrm{PLA}_{50}-b$-PEG- $b$-PLA ${ }_{50}$ (central block PEG $=20000 \mathrm{~g} \mathrm{~mol}^{-1}$; side blocks $\mathrm{PLA}_{50}=175000 \mathrm{~g} \mathrm{~mol}^{-1}$ ) to evaluate ex vivo the potential of PCL-TIB as macromolecular radio-opacifier at various weight ratios. PLA $_{50}$-PEG-PLA 50 with a high molecular weight (370 000 $\mathrm{g} \mathrm{mol}^{-1}$ ) was chosen as a non-X-rays visible resorbable thermoplastic model because it previously demonstrated interest as drug releasing coatings, drug releasing microparticles or as biomaterial to generate scaffolds for skin tissue engineering. ${ }^{4-49}$ Ratios of PCL-TIB and PLA $_{50}$-PEG-PLA $_{50}$ were adjusted to yield polymer blends containing $0,1,2.5,5,10$ and $20 \mathrm{wt} \%$ of iodine, which corresponds to PCL-TIB weight ratios in blends of $0 \mathrm{wt} \%$ PCL-TIB, $10 \mathrm{wt} \%$ PCL-TIB $_{3.5}, 25 \mathrm{wt} \%$ PCL-TIB $_{3.5}, 50 \mathrm{wt} \% \mathrm{PCL}^{-\mathrm{TIB}_{3.5}}, 50 \mathrm{wt} \% \mathrm{PCL}^{-\mathrm{TIB}_{8}}$ and $100 \mathrm{wt} \%$ PCL-TIB, , respectively.

\section{In vitro $\mathrm{X}$-ray imaging}

X-radiographs were obtained using a standard Elitys X-ray machine (Trophy radiology) kindly made available by M. Guilhem Romieu dentist in Prades-Le-Lez, France. Imaging parameters were as follow: sample-amplifier distance $5 \mathrm{~cm}$, angle $90^{\circ}, 70 \mathrm{kV}, 4 \mathrm{~mA}, 0.1 \mathrm{~s}$. Relative radio-opacity of samples was calculated by image analyses with respect to aluminum wedge of the same thickness. For this purpose, an aluminum scale with thicknesses ranging from 0.5 to $5.5 \mathrm{~mm}$ was used. Each image was analyzed using Image software to determine the sample grey index (GI). For each sample, GI was measured in various locations (between 6 to 10) and was then expressed as mean value \pm standard deviation. GI scored on a 255 -unit scale with white $=255$ and black $=0$. The X-ray absorbance ranged from $0 \%$ (no X-ray absorption) to $100 \%$ (full absorption) and was determined using eqn (1).

$$
A(\%)=100 \times\left(1-\left(\frac{\mathrm{GI}_{\mathrm{Al}}-\mathrm{GI}_{\mathrm{s}}}{255}\right)\right)
$$

with $A$ being the percentage of absorbance, $\mathrm{GI}_{\mathrm{s}}$ the grey index of sample and $\mathrm{GI}_{\mathrm{Al}}$ the grey index of aluminum wedge.

\section{Ex vivo X-ray imaging}

X-radiographs were obtained using a standard clinical Trixell X-ray machine (Moirans, France) with Surgivisiotractor interface. Imaging parameters were as follow: sample-amplifier distance $50 \mathrm{~cm}$, angle $90^{\circ}, 40 \mathrm{kV}, 30 \mathrm{~mA} \mathrm{~s}^{-1}, 1 \mathrm{~s}$. Chicken breast muscle ( $4 \mathrm{~cm}$ thickness) was chosen as an anamic ex vivo model. This model was transected longitudinally in the middle and samples were placed in cutting area at a depth of $c a$. $2 \mathrm{~cm}$ from the muscle surface. To evaluate the influence of degradation time on X-ray visibility, control plate at $0 \mathrm{wt} \%$ iodine and sample plates at 10 and $20 \mathrm{wt} \%$ iodine were placed in $8 \mathrm{~mL}$ of PBS (pH 7.4) at constant temperature $\left(37^{\circ} \mathrm{C}\right)$ under stirring for 6 weeks (stirring speed of $100 \mathrm{rpm}$ ). Degraded samples were then analyzed as described above. A $2 \mathrm{~mm}$ thick aluminum wedge placed next to the anatomic model was imaged with the samples and used as positive control.

\section{Cytocompatibility}

Mouse L929 fibroblasts (L929) were cultured in modified Eagle's medium (MEM) containing 10\% horse serum, penicillin $(100 \mu \mathrm{g}$ $\left.\mathrm{mL}^{-1}\right)$, streptomycin $\left(100 \mu \mathrm{g} \mathrm{mL} \mathrm{m}^{-1}\right)$, and glutamax $(1 \%)$. For each sample, three plates were punched out from the same PCL-TIB sample. Plates were disinfected in ethanol for 30 minutes before being immersed in a solution of sterile PBS containing penicillin and streptomycin $\left(1 \mathrm{mg} \mathrm{mL}{ }^{-1}\right)$ and incubated for $48 \mathrm{~h}$ at $37^{\circ} \mathrm{C}$. The plates were then rinsed 3 times with sterile PBS before being soaked for 12 hours in sterile PBS. These sterile PCL-TIB plates were stamped to fit the wells of 24-well cell culture plates. In vitro cytocompatibility was assessed by monitoring the proliferation of L929 fibroblasts on the surface of the plates. To do this, the plates were placed in polystyrene 24-well tissue culture plates (TCPS) and seeded with $1 \times 10^{4}$ L929 cells. Cell viability after 1,2 and 3 days was evaluated using the PrestoBlue ${ }^{\mathrm{TM}}$ assay that reflects the number of living cells present on a surface at a given time point. Culture medium was removed at scheduled time points and replaced by $1 \mathrm{~mL}$ of fresh medium containing $10 \%$ PrestoBlue $^{\mathrm{TM}}$. Fluorescence at $\lambda=530 \mathrm{~nm}\left(\lambda_{\mathrm{ex}}\right)$ and $\lambda=615 \mathrm{~nm}\left(\lambda_{\mathrm{em}}\right)$ was measured on a Victor X3 photometer (Perkin-Elmer). All data points and standard deviations correspond to measurements in triplicate.

\section{Results and discussion}

\section{Synthesis of radiopaque PCL}

One reported way for preparing X-ray radiopaque PCL is the ring opening copolymerization of $\varepsilon$-CL with functional $\varepsilon$-CL bearing heavy atoms like iodine. This strategy was followed by our group in the recent past to yield poly $(\alpha$-iodo- $\varepsilon$-caprolactone-co- $\varepsilon$-caprolactone). ${ }^{\mathbf{4 1 , 4 2}}$ Speaking of materials however, the synthesis of functional lactones does not appear as a convenient strategy as 
large amounts of products can barely be obtained. To overcome this limitation our group developed few years ago an anionic post-modification reaction that provided various functional PCLs with 5 to $15 \%$ of functional groups including poly $(\alpha$-iodo$\varepsilon$-caprolactone-co- $\varepsilon$-caprolactone) (PCL-I). ${ }^{40}$ In the case of PCL-I, low stability of the aliphatic carbon-iodine bond was encountered, which led to a rapid loss of X-ray visibility. With the aim to prepare a more stable radiopaque PCL suitable for implantation, the anionic post-polymerization modification strategy has been applied to yield PCL bearing triiodobenzoyl groups (PCL-TIB). Another expected advantage of TIB substitution compared to direct iodine substitution is the higher iodine content that is reachable for the same degree of substitution of the PCL backbone. PCL-TIB being designed a radio-opacifier additive, this increase is of benefit as less PCL-TIB should be required to induce $\mathrm{X}$-ray visibility, which should guaranty minimal impact on the polymer matrix properties.

Scheme 1 summarizes the synthesis of PCL-TIB. Triiodobenzoyl chloride (TIBC) was first prepared as an activated intermediate in a $60 \%$ yield (ESI Fig. S1 and S2 $\dagger$ ). TIBC was then reacted with PCL under anionic chemical modification conditions. The parameters of the PCL activation step with LDA and of the subsequent substitution with TIBC have been chosen in order to guaranty visibility while minimizing side reactions including backbone hydrolysis. Each step was run for 30 minutes, while the number of reactant equivalents and the temperature were varied (Table 1). The polymer chemical structure was characterized by ${ }^{1} \mathrm{H}-\mathrm{NMR}$ (ESI Fig. S3 $\dagger$ ). Substitution degree (SD) was calculated using eqn (2) by comparison of the integrations of the well-defined resonance peaks at 8.3 ppm and $7.6 \mathrm{ppm}$, corresponding to the aromatic protons of TIB group, with the integration of the resonance peak at $4.0 \mathrm{ppm}$, corresponding to a methylene of PCL.

$$
\mathrm{SD}(\%)=I_{8.3-7.6 \mathrm{ppm}} /\left(I_{4 \mathrm{ppm}} / 2\right) \times 100
$$

Depending on the reaction conditions a substitution degree ranging from $3.5 \%$ to $24 \%$ was obtained. As classically observed for this type of reaction, a strong impact on the molecular weight and dispersity was also observed. In more details, whereas the lowest SD of $3.5 \%$ could be obtained with
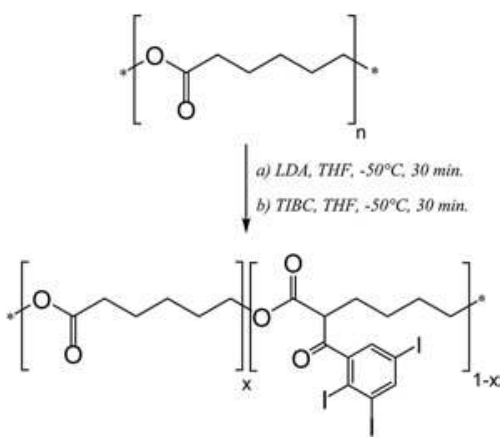

Scheme 1 Synthetic scheme for the preparation of poly( $\varepsilon$-caprolactone-co- $\alpha$-triiodobenzoate- $\varepsilon$-caprolactone) (PCL-TIB). a minimal impact on the molecular weight and dispersity $\left(M_{\mathrm{n}}\right.$ $\approx 24000 \mathrm{~g} \mathrm{~mol}^{-1}$ and $\left.\boxplus=1.7\right)$ compared to pristine PCL $\left(M_{\mathrm{n}} \approx\right.$ $32000 \mathrm{~g} \mathrm{~mol}^{-1}$ and $Ð=1.8$ ) (Fig. 1), a further increase of SD clearly had a strong impact on these macromolecular parameters (Table 1). In particular, for the highest SDs, a shoulder $\left(\mathrm{PCL}-\mathrm{TIB}_{12}\right)$ or even bimodality $\left(\mathrm{PCL}-\mathrm{TIB}_{24}\right)$ were observed on the chromatograms (not shown). For that reason, PCL-TIB ${ }_{24}$ was not further considered in this work and PCL-TIB 12 was only used in the preliminary in vitro visibility assessments. It is to note that molecular weight decrease is classically observed with the anionic activation of polyester, as a consequence of hydrolysis and backbiting side reactions. However, although remarkable in terms of influence on the final molecular weight, the observed decrease only corresponds to a very low extent of side reactions. It represents less than $0.2 \%$ hydrolysis of the ester groups initially present in the polymer chain in the case of the lower $\mathrm{SD}$, i.e. PCL-TIB ${ }_{3.5}$, and $c a$. $0.7 \%$ hydrolysis for PCL-TIB $_{12}$. In addition, this drawback should be put in perspective with a major advantage of the approach, that is, starting from commercially available PCL this one pot and time saving reaction allows the preparation of $c a .2 \mathrm{~g}$ batches of PCL-TIB in a single day, including reaction and purification.

Thermal properties of monomodal PCL-TIB were studied by DSC and TGA and results are reported in Table 2. Melting temperatures of PCL-TIB 3.5 were $\mathrm{ca} .10{ }^{\circ} \mathrm{C}$ lower than the ones of pristine PCL with $T_{\mathrm{m}_{1}}=52{ }^{\circ} \mathrm{C}$ and $T_{\mathrm{m}_{2}}=49{ }^{\circ} \mathrm{C}$ for PCL-TIB ${ }_{3.5}$ against $T_{\mathrm{m}_{1}}=62{ }^{\circ} \mathrm{C}$ and $T_{\mathrm{m}_{2}}=57{ }^{\circ} \mathrm{C}$ for PCL. The same observation was done on crystallization temperature, which is $17{ }^{\circ} \mathrm{C}$ for $\mathrm{PCL}^{-\mathrm{TIB}_{3.5}}$ against $23{ }^{\circ} \mathrm{C}$ for PCL. Similar results were obtained with $\mathrm{PCL}^{-\mathrm{TIB}_{8}}$ with as expected lower crystallinity and lower crystallization temperature compared to PCL-TIB PI.5 $_{\text {. }}$ These differences can be ascribed to the lower molecular weight of PCL-TIB compared to pristine PCL, as well as a lower crystallinity due to chains packing disturbance resulting from the TIB side group. This lower crystallinity is confirmed by the melting enthalpy values measured that are $c a$. twice lower for PCL-TIB compared to PCL. With aim to compare stability of PCL-I and PCL-TIB, thermogravimetric analyses were conducted on radiopaque PCLs with a similar iodine molar content of $10 \%$, PCL-TIB $_{3.5}$ and PCL-I ${ }_{10}(\mathrm{SD}=10 \%)$, that was synthesized according to the procedure previously reported. ${ }^{40}$ Thermograms (ESI Fig. S4 $\dagger$ ) showed that PCL-TIB 3.5 thermal degradation

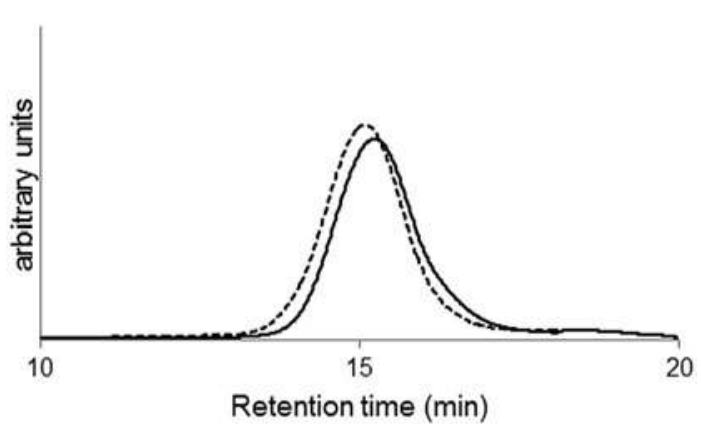

Fig. 1 SEC chromatograms of PCL (dashed line) and PCL-TIB 3.5 (plain line). 
Table 2 PCL-TIB thermal properties

\begin{tabular}{|c|c|c|c|c|}
\hline Sample & $T_{\mathrm{g}}\left({ }^{\circ} \mathrm{C}\right)$ & $\begin{array}{l}T_{\mathrm{m}_{1}} / \Delta H_{\mathrm{m}_{1}} \\
\left({ }^{\circ} \mathrm{C} ; \mathrm{J} \mathrm{g}^{-1}\right)\end{array}$ & $\begin{array}{l}T_{\mathrm{m}_{2}} / \Delta H_{\mathrm{m}_{2}} \\
\left({ }^{\circ} \mathrm{C} ; \mathrm{J} \mathrm{g}^{-1}\right)\end{array}$ & $T_{\mathrm{c}}\left({ }^{\circ} \mathrm{C}\right)$ \\
\hline PCL & $<-60{ }^{\circ} \mathrm{C}$ & $62 / 113$ & $57 / 78$ & 23 \\
\hline PCL-TIB $_{3.5}$ & $<-60{ }^{\circ} \mathrm{C}$ & $52 / 60$ & $49 / 44$ & 17 \\
\hline PCL-TIB $_{8}$ & $<-60{ }^{\circ} \mathrm{C}$ & $52 / 44$ & $48 / 41$ & 12 \\
\hline
\end{tabular}

occurred in the same range of temperature than for PCL with an onset temperature around $270{ }^{\circ} \mathrm{C}$ against $260{ }^{\circ} \mathrm{C}$. Under the same conditions PCL-I degraded much earlier than PCL-TIB with an onset temperature found at $c a .205{ }^{\circ} \mathrm{C}$ and degradation temperatures $T_{\mathrm{d} 5 \%}$ found at $269^{\circ} \mathrm{C}$ for PCL-I against $296{ }^{\circ} \mathrm{C}$ for PCL-TIB. This result confirms the higher thermal stability of PCL-TIB vs. PCL-I.

\section{In vitro X-ray imaging of PCL-TIB/PCL blends}

As a first evaluation of PCL-TIB as radio-opacifier for X-ray imaging, blends of PCL and PCL-TIB were prepared. Defined quantities of PCL-TIB substituted at $8 \%$ and $12 \%$ were used to yield final iodine weight contents ranging from 0 to $25 \mathrm{wt} \%$. Films with a thickness of $0.5 \mathrm{~mm}$ were imaged using Elitys (Trophy radiology) equipment (ESI Fig. S5 $\dagger$ ) and compared with an aluminum wedge of the same thickness. Grey index (scored on a 255 -unit scale with white $=255$ and black $=0$ ), relative absorption and attenuation per $\mu \mathrm{m}$ were calculated based on the X-ray images analyses and are listed in Table 3. Note that images were measured simultaneously, that is, grey values can be compared. A quasi-linear evolution of GI with respect to iodine weight percentage was obtained. Similar GI, and therefore attenuation per $\mu \mathrm{m}$ thickness, was obtained for the aluminum wedge and the PCL/PCL-TIB blend with as low as 15 wt $\%$ iodine. This result demonstrates the ability of PCL-TIB to induce X-ray absorption when used in polymer blends.

\section{Visual and mechanical evaluations of PCL-TIB/PLA ${ }_{50}-b$-PEG- $b$ - PLA 50 blends}

To further evaluate the potential of PCL-TIB as radio-opacifier for X-ray imaging, blends of PLA $_{50}-b$-PEG- $b$-PLA Fo $_{50}$ and

Table 3 Comparison of in vitro X-ray absorptions of PCL-TIB/PCL blends ( $0.5 \mathrm{~mm}$ thickness) and of aluminum wedge ( $0.5 \mathrm{~mm}$ thickness)

\begin{tabular}{llll}
\hline $\begin{array}{l}\text { Iodine content } \\
(\text { wt } \%)\end{array}$ & $\begin{array}{l}\text { Grey } \\
\text { index }\end{array}$ & $\begin{array}{l}\text { Relative } \\
\text { absorption }^{a}(\%)\end{array}$ & $\begin{array}{l}\text { Attenuation }^{b} \\
(\%) \text { per } \mu \mathrm{m} \text { thickness }\end{array}$ \\
\hline 0 & $15 \pm 3$ & 25 & 0.011 \\
5 & $26 \pm 7$ & 43 & 0.020 \\
10 & $33 \pm 8$ & 55 & 0.025 \\
15 & $64 \pm 9$ & 107 & 0.050 \\
25 & $82 \pm 7$ & 136 & 0.065 \\
Aluminum wedge & $60 \pm 8$ & 100 & 0.047
\end{tabular}

${ }^{a}$ Calculated with respect to grey index of the aluminum wedge.

${ }^{b}$ Calculated based on the grey index scale with white $=255$ and black $=0$.

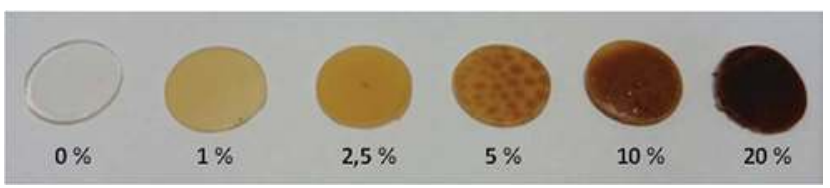

Fig. 2 Pictures of PCL-TIB/PLA $50-b-P E G-b-P L A_{50}$ blends with increasing contents of PCL-TIB. Percentages correspond to iodine weight ratios.

PCL-TIB were prepared. Custom made PLA ${ }_{50}-b$-PEG- $b$-PLA 50 copolymer was chosen as it was successfully used by our group to formulate drug releasing coatings and drug releasing microparticles, or to generate scaffolds for skin tissue engineering. ${ }^{4-49}$ Considering the variety of applications for this family of copolymers, it appears therefore as a good candidate for blending and radio-opacifying with PCL-TIB. Again, defined quantities of PCL-TIB substituted at $3.5 \%$ or $8 \%$ were used to yield final iodine weight contents ranging from 0 to $20 \mathrm{wt} \%$. The films obtained are shown in Fig. 2. Homogeneous films were obtained for low and high PCL-TIB contents $(1,2.5$ and $20 \mathrm{wt} \%$ iodine). In opposition, macroscopic phase separation was observed for PCL-TIB contents corresponding to $5 \mathrm{wt} \%$ iodine $(50 \mathrm{wt} \%$ PCL-TIB $_{3.5}$ ) and $10 \mathrm{wt} \%$ iodine (50 wt $\%$ PCL-TIB $_{8}$ ). Although PCL-TIB was present in the all sample, as demonstrated by the clear yellow color of the film, areas of higher PCL-TIB concentrations were observed under the form of brown spots. This result highlights a lower compatibility of the triblock copolymer and PCL-TIB when a $1: 1$ mass ratio is used. It is to note that phase separation was not observed in PCL blends, whatever the PCL-TIB concentration, which underlines the importance of the nature of polymers to be used in the blend, as well as the PCL-TIB/polymer ratio.

The impact of PCL-TIB 3.5 on the mechanical properties of the blends was then assessed. The tensile tests were performed on dogbone-style tensile specimens (ESI Fig. S6†). Blends with the

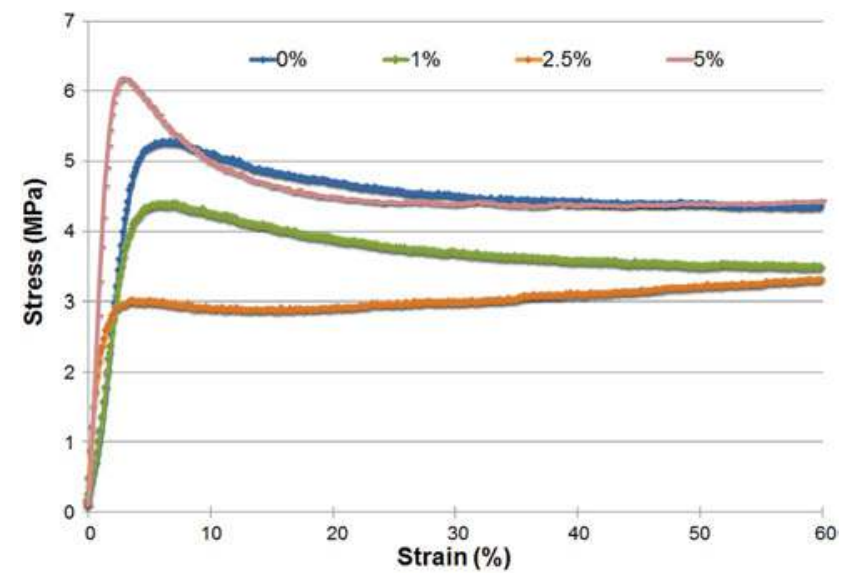

Fig. 3 Typical stress-strain tensile curves of PCL-TIB/PLA $A_{50}-b-P E G-$ $b$-PLA ${ }_{50}$ blends (GABO Eplexor ${ }^{\circledR} 1500 \mathrm{~N}$ testing machine, $25 \mathrm{~N}$ cell force, $5 \mathrm{~mm} \mathrm{~min}{ }^{-1}$ crosshead speed rate, $37^{\circ} \mathrm{C}$ ). Percentages correspond to iodine weight ratios; samples were not loaded to failure. 


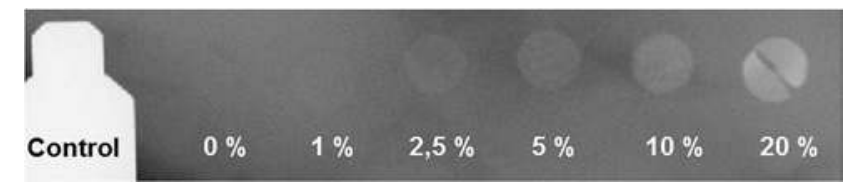

Fig. 4 Ex vivo $X$-ray images of PCL-TIB/PLA $A_{50}-b$-PEG- $b$-PLA $A_{50}$ blends implanted in a $4 \mathrm{~cm}$ thick anatomical model. Control corresponds to $2 \mathrm{~mm}$ thick aluminum wedge. Percentages correspond to iodine weight ratios (20 wt\% sample film shown is broken in two pieces; dark line in the middle of the sample corresponds to this fracture).

highest PCL-TIB content were too fragile and were therefore not tested. The other samples ( 1 to $5 \mathrm{wt} \%$ iodine) were all prepared with the same PCL-TIB 3.5 and were not loaded to failure as they present a rupture strain greater than the possibility of the testing machine. Typical tensile curves are shown in Fig. 3. The results present the nominal stress (force divided by the initial section) in function of strain (displacement divided by the initial length). The curves present an initial linear curve that can be assimilated to the elasticity of the material. The Young modulus is evaluated by fitting this part of the curve. The yield strain is defined as the end of this linear part. The values of the Young modulus and the yield strain are listed in Table 4. The increasing content of PCL-TIB seems to increase the stiffness of the material by increasing the Young modulus and reducing the yield strain. After the elastic part, the curves are very flat seeming to a creep test with an increasing deformation with a constant stress. It is to note that increasing contents of PCL-TIB 3.5 (if iodine content is no greater than $5 \mathrm{wt} \%$ ) do not change significantly the mechanical behavior of the PLA ${ }_{50}-b$-PEG- $b$-PLA ${ }_{50}$ with similar strain-stress curves profiles and characteristic values in a same range.

\section{Ex vivo X-ray imaging of PCL-TIB/PLA $A_{50}-b$-PEG- $b$-PLA 5 blends}

The radio-opacifying effect of PCL-TIB in the PCL-TIB/PLA ${ }_{50}-b$ PEG- $b-$ PLA $_{50}$ blends was evaluated under conditions mimicking implantation. Radiopaque sample films with $0.5 \mathrm{~mm}$ thickness were inserted in chicken breast muscle that was chosen as anatomical ex vivo model. All samples were then imaged the same day under the same conditions (see experimental parts for details). It is first important to note that PLA $A_{50}-b$-PEG- $b-$ PLA $_{50}$ sample without PCL-TIB did not demonstrate any additional X-ray absorption compared to the surrounding tissue (Fig. 4). It is to note that X-ray absorption of anatomical model was not nil as shown by the greyish color of tissues and the calculated absorption of $50 \%$ (Table 4).

In opposition, all samples containing PCL-TIB exhibited a clear contrast and were visible in the anatomical model. Remarkably, even iodine content in the blend as low as $1 \mathrm{wt} \%$ made the sample visible. This visibility was however considered too weak by surgeons for practical use. An iodine content of $2.5 \mathrm{wt} \%$ is therefore the lowest one with respect to practical clinical imaging. Little difference between blends containing 2.5 and $5 \mathrm{wt} \%$ iodine was observed in this X-ray imaging experiment. This was due to the inhomogeneity of muscle and
Table 4 Mechanical properties and percentage of $X$-ray absorption of polymer blends samples (600 $\mu \mathrm{m}$ thickness) ex vivo before and after degradation

\begin{tabular}{|c|c|c|c|c|}
\hline $\begin{array}{l}\text { Iodine content } \\
\text { (wt } \%)\end{array}$ & $\begin{array}{l}E \\
(\mathrm{MPa})\end{array}$ & $\begin{array}{l}Y \\
(\%)\end{array}$ & $\begin{array}{l}\text { Absorption } \\
\text { at } t_{0}{ }^{a, b}(\%)\end{array}$ & $\begin{array}{l}\text { Delta absorption } \\
\text { at } 6 \text { weeks }{ }^{a, c}(\%)\end{array}$ \\
\hline Muscle & - & - & 47 & 0 \\
\hline 0 & 0.8 & 5.2 & 50 & 0 \\
\hline 1 & 0.9 & 4.2 & 52 & nd \\
\hline 2.5 & 2.4 & 2.3 & 55 & nd \\
\hline 5 & 2.9 & 3.3 & 55 & nd \\
\hline 10 & nd & nd & 58 & -0.4 \\
\hline 20 & nd & nd & 73 & -0.4 \\
\hline $\begin{array}{l}\text { Aluminum } \\
\text { wedge }\end{array}$ & - & - & 96 & - \\
\hline
\end{tabular}

of the above mentioned inhomogeneity of the $5 \mathrm{wt} \%$ blend that is visible in Fig. 4 and emphasized in Fig. S7 (ESI Fig. S7†) with clear isolated spots exhibiting higher contrast compared to the rest of the sample. Samples with 10 and $20 \mathrm{wt} \%$ iodine were obviously the most visible and exhibited X-ray absorption of $60 \%$ and $76 \%$, respectively, compared to the $2 \mathrm{~mm}$ thick aluminum wedge. This result confirms that image contrast is proportional to the amount of iodine.

Stability of X-ray visibility over time was assessed using aged sample plates containing 0,10 or $20 \mathrm{wt} \%$ iodine. Samples were placed for 6 weeks in PBS at $37^{\circ} \mathrm{C}$ under stirring to mimic physiological conditions prior to implantation in an anatomical model for X-ray imaging. The non-degraded samples were implanted in the same anatomical model for comparison (Fig. 5). Degraded samples remained highly visible after 6 weeks. In addition, no difference of contrast was found between the degraded and non-degraded samples. A negligible variation of X-ray absorption ( $0.4 \%)$ was calculated from the GI values. These results confirm the high stability of the carboniodine bond in PCL-TIB and the potential of this copolymer to

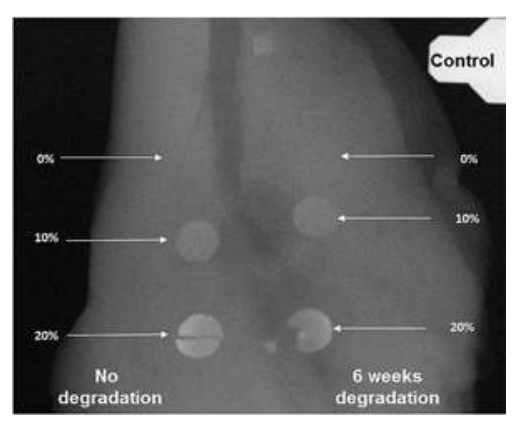

Fig. 5 Ex vivo $X$-ray images of non-degraded (left-hand side) and degraded (right-hand side) PCL-TIB/PLA $A_{50}-b-P E G-b-P L A_{50}$ blends sample plates implanted in a $4 \mathrm{~cm}$ thick anatomical model. Control corresponds to $2 \mathrm{~mm}$ thick aluminum wedge. Percentages correspond to iodine weight ratios. 
be used as macromolecular radio-opacifier for implantable medical devices.

\section{Cytocompatibility of radiopaque PCL-TIB/PLA ${ }_{50}-b$-PEG- $b$ - PLA $_{50}$ blends}

X-ray absorption capability is the main parameter to consider PCL-TIB as a potential macromolecular radio-opacifying agent. However, in the frame of medical applications and implantable medical devices, another critical parameter is the biocompatibility of the biomaterial towards tissues and cells. For that reason, and as a first approach, an evaluation of cells proliferation was performed on films to assess the cytocompatibility of PCL-TIB/PLA ${ }_{50}-b$-PEG- $b$-PLA 50 blends and to determine whether they are suitable for cell culture and cell-contacting biomedical applications. Tests were conducted on the L929 fibroblast cell line, as recommended by International and European standards (ISO 10993-5:2009). Films with iodine contents in the range 1-5 wt $\%$ were tested. Fig. 6 shows the proliferation at 1, 3 and 7 days of L929 murine fibroblasts on the radiopaque blends compared to pure $\mathrm{PLA}_{50}-b$-PEG- $b$-PLA 50 ( 0 wt $\%$ iodine) and TCPS positive control. L929 fibroblasts adhered and proliferated on the samples. In more details, following an initial period up to 3 days with limited proliferation for all samples and controls, fast proliferation was then observed. As expected, proliferations on blends were slower than on TCPS positive control, but were significant with relative proliferations in the range $70-84 \%$ for blends containing $2.5 \mathrm{wt} \%$ and $5 \mathrm{wt} \%$, respectively. It is of importance to note that cells proliferation was better on PCL-TIB/PLA 50 - $b$-PEG- $b$-PLA 50 blends compared to PLA $_{50}-b$-PEG$b$-PLA 50 and was improved with increasing PCL-TIB contents. This is remarkable considering that block copolymers of PLA and PEG are widely recognize as cytocompatible materials and have a long track record as biomaterials. This result confirms that PCL-TIB appears to be suitable for the growth of fibroblasts and cell-contacting applications and may be of interest for the design of X-ray visible medical devices.

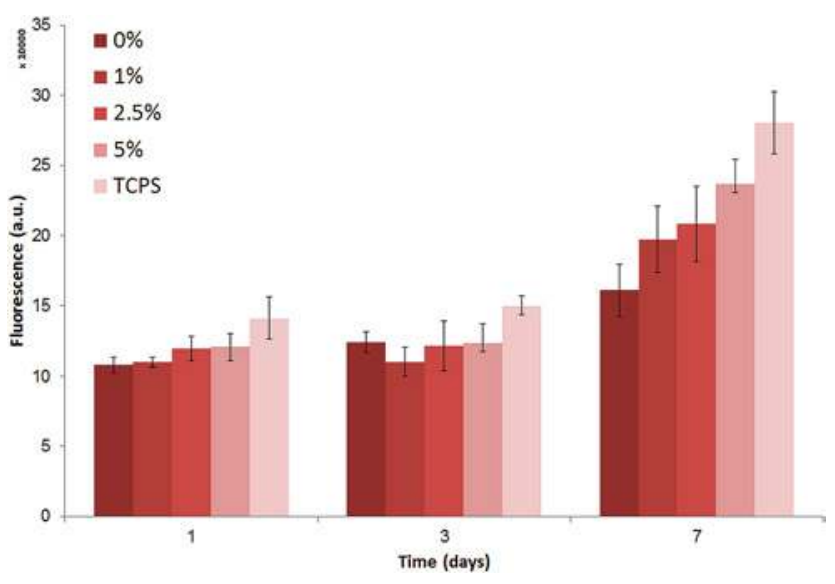

Fig. 6 L929 fibroblasts proliferation on PCL-TIB/PLA ${ }_{50}-b-P E G-b-$ PLA 50 blends ( 1 to $5 \mathrm{wt} \%$ iodine) compared to pristine PCL films ( $0 \mathrm{wt} \%$ iodine) and TCPS control at 1, 3, and 7 days (data are expressed as means \pm SD and correspond to measurements in triplicate).

\section{Conclusions}

Poly( $\varepsilon$-caprolactone-co- $\alpha$-triiodobenzoate- $\varepsilon$-caprolactone) (PCLTIB) was synthesized with substitution ratios ranging from 3.5 to $24 \%$. This family of macromolecular X-ray contrast agents could be blended in (co)polyester matrices to induce X-ray opacity. Mechanical properties of the blends with up to $5 \mathrm{wt} \%$ iodine were not significantly impacted by PCL-TIB $_{3.5}$ compared to the raw polymer matrices. Radio-opacity was observed in ex vivo model with $1 \mathrm{wt} \%$ iodine although for practical use a 2.5 wt $\%$ should be preferred. In addition, PCL-TIB was shown to be stable enough to make blends radiopaque, even after 6 weeks degradation, and compatible with L929 fibroblasts proliferation. In conclusion, PCL-TIB copolymers appear to be promising candidates as additive for implantable medical devices requiring X-ray imaging abilities.

\section{Acknowledgements}

The authors thank the University of Montpellier for the participation to Mr Rémi Samuel funding (University Montpellier 1; Trainee Program 2013-2014), Ms Majda Akrach and Ms Mélanie Bayarri for their help on in vitro X-ray experiments, Mr Guilhem Romieu for access to his X-ray Elitys equipment. Authors also thank Mr Quentin Breche for his help on the GABO Eplexor ${ }^{\circledR}$ $1500 \mathrm{~N}$ testing machine and $\mathrm{Mr}$ Benjamin Spencer from GMCAO for his help on ex vivo imaging.

\section{References}

1 S. M. Janib, A. S. Moses and J. A. MacKay, Adv. Drug Delivery Rev., 2010, 62, 1052-1063.

2 B. Nottelet, V. Darcos and J. Coudane, Eur. J. Pharm. Biopharm., 2015, DOI: 10.1016/j.ejpb.2015.06.023.

3 Z. Y. Wang, T. Chang, L. Hunter, A. M. Gregory, M. Tanudji, S. Jones and M. H. Stenzel, Aust. J. Chem., 2014, 67, 78-84.

4 N. Anton and T. F. Vandamme, Pharm. Res., 2014, 31, 20-34.

5 S. Dawlee, A. Jayakrishnan and M. Jayabalan, J. Mater. Sci.: Mater. Med., 2009, 20, 243-250.

6 S. Kiran, N. R. James, R. Joseph and A. Jayakrishnan, Biomaterials, 2009, 30, 5552-5559.

7 M. Marcos, P. Cano, P. Fantazzini, C. Garavaglia, S. Gomez and L. Garrido, Magn. Reson. Imaging, 2006, 24, 89-95.

8 F. Hallouard, S. Briancon, N. Anton, X. Li, T. Vandamme and H. Fessi, J. Pharm. Sci., 2013, 102, 4150-4158.

9 F. Hallouard, S. Briancon, N. Anton, X. Li, T. Vandamme and H. Fessi, Pharm. Res., 2013, 30, 2023-2035.

10 V. P. Torchilin, Adv. Drug Delivery Rev., 2002, 54, 235-252.

11 A. J. L. Villaraza, A. Bumb and M. W. Brechbiel, Chem. Rev., 2010, 110, 2921-2959.

12 M. Vert, Prog. Polym. Sci., 2007, 32, 755-761.

13 M. Vert, J. Mater. Sci.: Mater. Med., 2009, 20, 437-446.

14 B. Nottelet, C. Di Tommaso, K. Mondon, R. Gurny and M. Moller, J. Polym. Sci., Part A: Polym. Chem., 2010, 48, 3244-3254.

15 M. A. Woodruff and D. W. Hutmacher, Prog. Polym. Sci., 2010, 35, 1217-1256. 
16 B. C. Thanoo, M. C. Sunny and A. Jayakrishnan, Biomaterials, 1991, 12, 525-528.

17 B. C. Thanoo and A. Jayakrishnan, Biomaterials, 1990, 11, 477-481.

18 F. Luderer, I. Begerow, W. Schmidt, H. Martin, N. Grabow, C. M. Buenger, W. Schareck, K.-P. Schmitz and K. Sternberg, J. Biomater. Appl., 2013, 28, 219-231.

19 C. Shasteen, S. M. Kwon, K. Y. Park, S. Y. Jung, S. H. Lee, C. G. Park, M. H. Kim, S. Kim, W.-C. Son, T. H. Choi and Y. B. Choy, J. Biomed. Mater. Res., Part B, 2013, 101, 320-329.

20 T. Lamsa, H. Jin, J. Mikkonen, J. Laukkarinen, J. Sand and I. Nordback, Pancreatology, 2006, 6, 301-305.

21 I. Nordback, S. Raty, J. Laukkarinen, S. Jarvinen, A. Piironen, J. Leppiniemi, M. Kellomaki and J. Sand, Pancreatology, 2012, 12, 264-271.

22 L. Mazzocchetti, M. Scandola and A. Pollicino, Polymer, 2008, 49, 5215-5224.

23 L. Mazzocchetti, E. Cortecchia and M. Scandola, ACS Appl. Mater. Interfaces, 2009, 1, 726-734.

24 J. L. Pariente, L. Bordenave, R. Bareille, C. Ohayon-Courtes, C. Baquey and M. Le Guillou, Biomaterials, 1999, 20, 523527.

25 W. Wang, J. Liu, C. Li, J. Zhang, J. Liu, A. Dong and D. Kong, J. Mater. Chem. B, 2014, 2, 4185-4192.

26 D. Mawad, H. Mouaziz, A. Penciu, H. Mehier, B. Fenet, H. Fessi and Y. Chevalier, Biomaterials, 2009, 30, 5667-5674.

27 F. Mottu, D. A. Rufenacht, A. Laurent and E. Doelker, Biomaterials, 2002, 23, 121-131.

28 A. Galperin and S. Margel, Biomacromolecules, 2006, 7, 26502660.

29 D. Horak, M. Metalova and F. Rypacek, J. Biomed. Mater. Res., 1997, 34, 183-188.

30 M. A. B. Kruft, A. Benzina, F. Bar, F. H. Vanderveen, C. W. M. Bastiaansen, R. Blezer, T. Lindhout and L. H. Koole, J. Biomed. Mater. Res., 1994, 28, 1259-1266.

31 M. A. B. Kruft, A. Benzina, R. Blezer and L. H. Koole, Biomaterials, 1996, 17, 1803-1812.

32 N. Moszner, U. Salz, A. M. Klester and V. Rheinberger, Angew. Makromol. Chem., 1995, 224, 115-123.

33 K. Saralidze, Y. B. J. Aldenhoff, M. L. W. Knetsch and L. H. Koole, Biomacromolecules, 2003, 4, 793-798.
34 B. Vazquez, M. P. Ginebra, F. J. Gil, J. A. Planell, A. L. Bravo and J. San Roman, Biomaterials, 1999, 20, 2047-2053.

35 C. Zaharia, T. Zecheru, M. F. Moreau, F. Pascaretti-Grizon, G. Mabilleau, B. Marculescu, R. Filmon, C. Cincu, G. Staikos and D. Chappard, Acta Biomater., 2008, 4, 17621769.

36 N. R. James, J. Philip and A. Jayakrishnan, Biomaterials, 2006, 27, 160-166.

37 S. Kiran, N. R. James, A. Jayakrishnan and R. Joseph, J. Biomed. Mater. Res., Part A, 2012, 100, 3472-3479.

38 M. D. Hindenlang, A. A. Soudakov, G. H. Imler, C. T. Laurencin, L. S. Nair and H. R. Allcock, Polym. Chem., 2010, 1, 1467-1474.

39 K. A. Aamer, K. L. Genson, J. Kohn and M. L. Becker, Biomacromolecules, 2009, 10, 2418-2426.

40 B. Nottelet, J. Coudane and M. Vert, Biomaterials, 2006, 27, 4948-4954.

41 S. El Habnouni, S. Blanquer, V. Darcos and J. Coudane, J. Polym. Sci., Part A: Polym. Chem., 2009, 47, 6104-6115.

42 S. El Habnouni, V. Darcos and J. Coudane, Macromol. Rapid Commun., 2009, 30, 165-169.

43 T. R. Olsen, L. L. Davis, S. E. Nicolau, C. C. Duncan, D. C. Whitehead, B. A. Horn and F. Alexis, Acta Biomater., 2015, 20, 94-103.

44 C. Rode, A. Schmidt, R. Wyrwa, J. Weisser, K. Schmidt, N. Moszner, R. P. Gottlober, K. Heinemann and M. Schnabelrauch, Polym. Int., 2014, 63, 1732-1740.

45 L. Sang, Z. Y. Wei, K. L. Liu, X. H. Wang, K. D. Song, H. Wang and M. Qi, J. Biomed. Mater. Res., Part A, 2014, 102, 11211130.

46 A. L. Carbone, M. Song and K. E. Uhrich, Biomacromolecules, 2008, 9, 1604-1612.

47 X. Garric, O. Guillaume, H. Dabboue, M. Vert and J. P. Moles, J. Biomater. Sci., Polym. Ed., 2012, 23, 1687-1700.

48 A. K. Jain, A. K. Goyal, N. Mishra, B. Vaidya, S. Mangal and S. P. Vyas, Int. J. Pharm., 2010, 387, 253-262.

49 M. Morille, V. T. Tran, X. Garric, J. Cayon, J. Coudane, D. Noel, M. C. Venier-Julienne and C. N. Montero-Menei, J. Controlled Release, 2013, 170, 99-110. 